\title{
Significance of Sonological Evaluation of Nuchal Translucency and Correlation with Pregnancy Outcome
}

\author{
M Raksha $^{1}$, KVN Dhananjaya ${ }^{2}$, KV Malini $^{3}$, Aparna Baliga $^{4}$
}

\begin{abstract}
Aims and objectives: To determine the effectiveness of the first-trimester nuchal translucency (NT) scan and prospective study with pregnancy outcome. (1) The study involves prenatal sonological evaluation of NT between 11 weeks and 13 weeks 6 days of gestation. (2) To correlate NT and congenital anomalies.

Materials and methods: Study design: This study was performed on pregnant women with gestational age of 11 weeks and 13 weeks 6 days at Kasturba Medical College and Govt. Lady Goschen Hospital, Mangaluru, from March 2, 2009 to March 10, 2011. Pregnant women undergone screening are followed up till delivery and assessment of congenital anomalies done. Inclusion criteria: (1) Pregnant women with gestational age of 11 weeks and 13 weeks 6 days. (2) Crown-rump length between $45 \mathrm{~mm}$ and $84 \mathrm{~mm}$. Subjects: Subjects are screened with ultrasonography and data entered. The subjects are followed up till the pregnancy outcome. The clinical assessment of the newborn baby was done to look for any congenital anomalies. The statistical analysis was done by using the Chi-square test. $p<0.05$ is considered to be significant. Techniques: (1) NT measurements done in the sagittal view of the fetus in the neutral position. (2) Magnification was such that only upper two-thirds of fetus were included in images. (3) Maximal subcutaneous translucency overlying neck was measured. (4) Measurement was taken with the horizontal lines placed on the lines that define the nuchal translucency thickness.

Results: (1) Increase in NT is associated with congenital abnormalities. (2) Increased NT is 551.41 times likely to have anomalies compared with normal NT.

Conclusion: Nuchal translucency is a strong predictor of congenital and chromosomal anomalies.

Keywords: Chromosomal anomalies, First trimester, Nuchal translucency, Prospective study.

Journal of South Asian Federation of Obstetrics and Gynaecology (2019): 10.5005/jp-journals-10006-1692
\end{abstract}

\section{INTRODUCTION}

Only over the past 20 years identifying fetuses with Down syndrome with the help of ultrasound has become a routine practice. Earlier, only women over the age of 35 years were offered amniocentesis, this led to very low detection of the Down syndrome in infant population, and a large number of fetuses with Down syndrome were undetectable prenatally. ${ }^{1}$ Majority of the fetuses that are affected tend to get missed easily; however, $25-33 \%$ of fetuses with Down syndrome have major malformations that are recognized in the second trimester ultrasonographically. ${ }^{2}$

Ultrasound imaging has improved quality over the past two decades. Many features of infants with Down syndrome have been picked up, like small nose, redundant skin at the neck, short stature, and flat facies. ${ }^{3}$ Specific ultrasound features such as pyelectasis, hyperechoic bowel, and echogenic intracardiac focus are used as markers to identify fetuses as high risk for Down syndrome. ${ }^{4}$

In Down syndrome, there is an extra chromosome, "21," resulting in varying degrees of mental handicap. As the maternal age increases, the risk of having a child with Down syndrome also increases, especially over the age of 35 years. ${ }^{5}$

However $70 \%$ of Down syndrome babies are born to mothers below the age of 35 years and hence there is a need for screening pregnant women of all ages to assess the risk of Down syndrome. ${ }^{6}$

The risk for many of the chromosomal defects increases with maternal age. For a woman 35 years of age, who has had a previous baby with trisomy 21 , the risk at 12 weeks of gestation increases from 1 in $249(0.40 \%)$ to 1 in 87 (1.15\%); for a woman 25 years of age, it increases from 1 in $946(0.106 \%)$ to 1 in $117(0.856 \%){ }^{7}$

\footnotetext{
1,3 Department of Obstetrics and Gynecology, Bangalore Medical College and Research Institute, Bengaluru, Karnataka, India

${ }^{2}$ Department of Radiology, Kasturba Medical College, Mangaluru, Karnataka, India
}

${ }^{4}$ Department of Obstetrics and Gynecology, Abhayahasta Multispeciality Hospital, Bengaluru, Karnataka, India

Corresponding Author: Raksha M, Department of Obstetrics and Gynecology, Bangalore Medical College and Research Institute, Bengaluru, Karnataka, India, Phone: +91 9611336004, e-mail: drraksha.m@gmail.com

How to cite this article: Raksha M, Dhananjaya KVN, Malini KV, et al. Significance of Sonological Evaluation of Nuchal Translucency and Correlation with Pregnancy Outcome. J South Asian Feder Obst Gynae 2019;11(4):225-229.

Source of support: Nil

Conflict of interest: None

Nuchal translucency (NT) is nothing but the normal subcutaneous fluid-filled space between the overlying skin and the back of the fetal neck. This area can be measured accurately on ultrasound between 11 weeks and $13^{+6}$ weeks of gestation. It is seen that greater the NT measurement, the higher is its association with major structural malformations, adverse pregnancy outcome, Down syndrome, and other aneuploidy.

It is believed that the increase in NT is caused by fluid accumulation in the nuchal region because of delayed development of the lymphatic system, abnormal aortic isthmic narrowing, other fetal cardiovascular defects, or abnormalities in the extracellular matrix. ${ }^{8}$ 
Nuchal translucency screening had a $77 \%$ sensitivity for Down syndrome and a $5 \%$ false-positive rate. ${ }^{9,10}$

\section{Interpretation of NT}

Naturally, there is an increase of NT measurement by $17 \%$ per week. This should be taken into account when calculating threshold levels for use with an increased NT. It is not appropriate to choose a single millimeter cutoff to define a specific NT measurement as abnormal or select a pregnancy that warrants invasive prenatal diagnostic testing. ${ }^{11}$

\section{NT and Aneuploidy}

Nuchal translucency thickness and the prevalence of chromosomal defects, major fetal anomalies, miscarriage, and fetal death are directly proportional to each other. ${ }^{12}$

An ultrasound evaluation of the fetus at $11-13^{+6}$ weeks of gestation, starting with the NT measurement, will help to accurately pick up chromosomal abnormalities and many nonchromosomal defects. $^{13}$

\section{Materials and Methods}

\section{Study Design: Prospective Study}

The study was done from March 2, 2009, to March 10, 2011, at Kasturba Medical College Hospital, Department of Radiodiagnosis, Attavar, Mangaluru, and Lady Goschen Hospital, Mangaluru.

The data were collected from women who were pregnant in whom the fetal NT thickness was measured between 11 weeks and 13 weeks 6 days of gestation during the period from March 2, 2009 to March 10, 2011. The outcome of the pregnancy was obtained from the hospital records.

The tool for examination of the fetus is a high-resolution real-time Ultrasound Machine Logiq 500. The transabdominal ultrasound probe used for scanning was a curvilinear probe with frequency band width of 3.5-5 MHz. The other facilities that are necessary to produce an atmosphere of security, comfort, and cooperation to complete the examination are also available like variable intensity lighting, individual linen, privacy screens, and lockable doors.

\section{Study Population}

All pregnant mothers presenting at Kasturba Medical College Hospital and Lady Goschen Hospital for routine antenatal scan from 11 weeks to 13 weeks 6 days of gestation who had fetal NT done by radiologists.

Our study population includes all patients from India who have had their antenatal scanning done at $11-13^{+6}$ weeks at Kasturba Medical College Hospital and Lady Goschen Hospital.

\section{Method}

All pregnant women between 11 weeks and $13^{+6}$ weeks of gestation were offered counseling before the screening. In the counseling, the patients were made aware of the uses of ultrasound at $11-13^{+6}$ weeks of gestation (such as to date the pregnancy accurately, to diagnose multiple pregnancy, to diagnose the viability of the fetus, to assess the chance of Down syndrome and other fetal abnormalities/ chromosomal abnormalities by measuring fetal NT).

After counseling, pregnant women were offered ultrasonography. The scans were carried out by a trained radiologist.

During the scan, uterine anomaly, cervix, internal os, adnexa, NT, and any structural abnormalities were looked for.
After the scan, the estimated chance for having Down syndrome or other fetal abnormalities was discussed with the pregnant woman and her family.

Our institution is registered under the PNDT Act and will follow the rules and regulations according to the act.

All fetuses that underwent NT scan and had normal NT or increased NT continued their pregnancy and detailed examination for structural abnormalities, major and minor markers, was done.

If lethal anomaly is detected at anomaly scan, pregnancy was terminated. If congenital anomalies were not picked up, fetal echocardiography was done to detect any congenital cardiac defect.

If no lethal cardiac defect detected, pregnancy was continued followed by interval growth scan. After delivery, the baby was evaluated by the pediatrician for anomalies.

\section{Inclusion Criteria}

- Gestational age: for NT 11 weeks to 13 weeks 6 days.

- Well-documented last menstrual period (known LMP with regular menstrual cycles or confirmed with early trimester pregnancy scans).

- Crown-rump length (CRL): measurement between $44 \mathrm{~mm}$ and $84 \mathrm{~mm}$.

\section{Exclusion Criteria}

The patients who do not attend the scan within the specified period of gestational weeks will be excluded from the study.

\section{Technique for Evaluation of NT with Images}

A reliable measurement of NT can be obtained by appropriate training and following a standard technique in order to make sure that the results among different operatives are uniform.

In our study, we used trans abdominal scan (TAS) as patient acceptability is less with trans vaginal scar (TVS).

\section{Image and Measurement}

For the measurement of fetal NT, a high-resolution USG machine with a video loop function is needed. The calipers used will provide measurements to one decimal point. In almost $95 \%$ of the cases, fetal NT can be measured successfully by transabdominal ultrasound examination. However in the others, a transvaginal sonography has to be done. The results from both are similar. ${ }^{14}$

Figure 1 shows the following:

A: The fetus should be in neutral position for NT to be measured.

$B$ : Calipers should be placed perpendicular to the fetal body axis and on the inner borders of the nuchal fluid - the transverse bar of the caliper should be such that it is hardly visible as it merges with the white line of the border and not in the nuchal fluid.

Guidelines by the Fetal Medicine Foundation to Maximize Good Quality of NT Ultrasound: ${ }^{15}$ the gestation should be $11^{1 / 2}-13^{+6}$ weeks and the fetal crown-rump length should be $45-84 \mathrm{~mm}$.

- Nuchal translucency ultrasound should only be performed by a radiologist certified in the technique.

- A mid-sagittal section of the fetus, for the measurement of fetal crown-rump length, should be obtained and the NT should be measured with the fetus in the neutral position. When the fetal neck is hyperextended the measurement can be increased by $0.6 \mathrm{~mm}$ and when the neck is flexed, the measurement can be decreased by $0.4 \mathrm{~mm}$.

- Only fetal head and upper thorax should be included for measurement of NT. The magnification should be as large as 

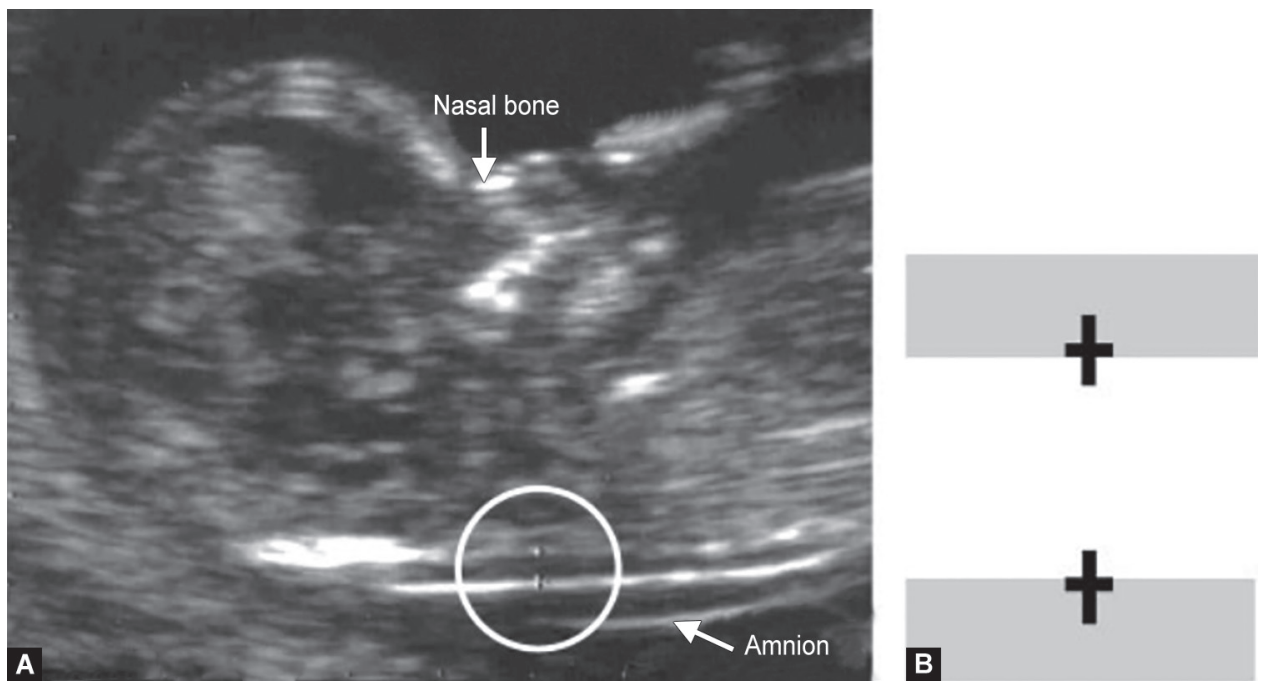

Figs $1 \mathrm{~A}$ and $\mathrm{B}$ : Measurement of nuchal translucency

possible and always such that each slight movement of the calipers produces $0.1 \mathrm{~mm}$ change in the measurement.

- The subcutaneous translucency between the soft tissue overlying the cervical spine and the skin should be measured. It should be the maximum thickness.

- The calipers must be placed perpendicular to the fetal body axis and on the inner borders of the nuchal fluid-the transverse bar of the caliper should be on the white line of the border and not in the nuchal fluid. Generally, three measurements are taken during the scan and the maximum one is recorded.

- We should take care to differentiate between fetal skin and amnion because both appear as thin membranes during this gestation. The best way to evaluate the amnion and skin is to watch the fetus during movement.

- Ethnic origin, diabetic control, fetal gender, cigarette smoking, conception by assisted reproductive techniques, bleeding in early pregnancy, or parity/gravidity does not show any relevant differences in the NT measurement.

- There is less than $0.5 \mathrm{~mm}$ difference in the intra-and interobserver differences in the fetal NT measurement in $95 \%$ of cases.

\section{Statistical Analysis}

\section{Statistical Methods}

In our study, descriptive statistical analysis has been done. Categorical measurements results are presented in number (\%) and continuous measurements results are presented on mean \pm SD. The $5 \%$ level of significance is assessed. The single-proportion $Z$ test is used to as the screening test to measure the detection rate of positive cases for significance.

\section{- $Z$ test for a binomial distribution (proportion)}

The objective is to look at the significance of the difference between the $p_{0}$, the observed proportion $p$, and the assumed proportion.

$$
Z=\frac{\left(! p-p_{0} !\right)-1 / 2 n}{\sqrt{p_{0} q_{0} / n}}
$$

- Significant figures and suggestive significance ( $p$ value: $0.05<p<0.10)$
${ }^{*}$ Moderately significant ( $p$ value: $0.01<p \leq 0.05$ )

**Strongly significant ( $p$ value: $p \leq 0.01$ )

The statistical software SPSS 11.5 was used for data analysis. Excel and Microsoft word have been used to prepare tables, graphs, etc.

\section{Results}

A total of 1,122 pregnant women who had an antenatal NT scan between 11 weeks and $13^{+6}$ weeks of gestation were selected into the study. A total of 1,122 fetuses were included. All 1,122 women were followed up till the end of their pregnancies.

Our study population involves minimum age of 18 years and maximum age of 42 years. Most of our patients are in the 21-30 years (69.3\%) age group and the mean maternal age was 28.26 years (SD: 4.660) as compared to Western data where the peak age being 31 years. The percentage of patients aged 30 years and above was $28.8 \%(n=323)$. Women aged $<20$ years are 22 (2.0\%), 21-30years are 777 (69.3\%), 31-40 years are $317(28.3 \%)$, and $>40$ years are $6(0.5 \%)$ as shown in Table 1.

In our study population, 605 women are primigravida and 517 women are multigravida.

Among 1,122 study subjects, number of fetuses born with congenital anomalies are 70 (6.2\%) and with no congenital anomaly are 1,052 (93.8\%) as shown in Figure 2.

The cutoff value for NT is taken as $3 \mathrm{~mm}$. The NT value less than $3 \mathrm{~mm}$ is considered as normal and the NT value more than $3 \mathrm{~mm}$ is considered as high NT. Mean NT is $2.204 \mathrm{~mm}$ and standard deviation is $1.1028 \mathrm{~mm}$.

The total number of fetuses with normal NT values are 936 (83.4\%) with 1 fetus is having congenital anomaly and 935 fetuses with no congenital anomaly. And fetuses with high NT values are 186 (16.6\%) with 69 fetuses are having congenital anomalies and 117 fetuses with no congenital anomaly.

Table 1: Age group distribution of study subjects $(n=1,122)$

\begin{tabular}{lcc}
\hline Age group (years) & Numbers & Percent \\
\hline$<20$ & 22 & 2.0 \\
$21-30$ & 777 & 69.3 \\
$31-40$ & 317 & 28.3 \\
$>41$ & 6 & 0.5 \\
Total & 1,122 & 100.0 \\
\hline
\end{tabular}




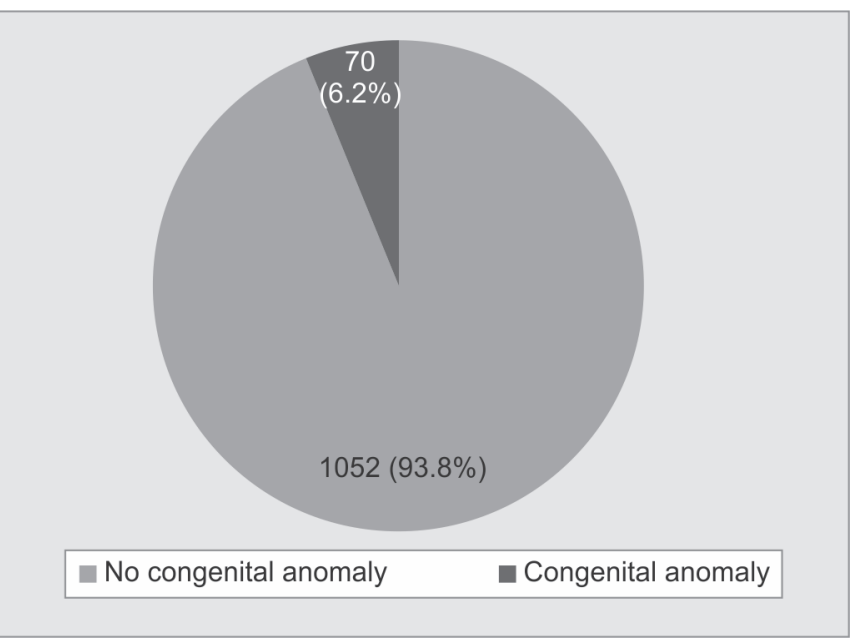

Fig. 2: Frequency of congenital anomalies in a study group $(n=1,122)$

Table 2: Distribution of normal and high nuchal translucency among study subjects

\begin{tabular}{lccc}
\hline Age group (years) & Normal NT (\%) & High NT (\%) & Total (\%) \\
\hline$<20$ & $12(1)$ & $10(0.9)$ & $22(2.0)$ \\
$21-30$ & $651(58.1)$ & $126(11.2)$ & $777(69.3)$ \\
$31-40$ & $267(23.7)$ & $50(4.5)$ & $317(28.3)$ \\
$>40$ & $6(0.5)$ & 0 & $6(0.5)$ \\
Total & $936(83.4)$ & $186(16.6)$ & $1,122(100)$ \\
\hline
\end{tabular}

Increase in NT is 551.41 times likely to have anomalies compared to normal NT (odds ratio $=551.41$ ).

Number of fetuses having normal NT in $<20$ years age group is $12,21-30$ years is $651,31-40$ years is 267 , and $>40$ years is 6 . Number of fetuses having high NT in the $<20$ years age group is 10 , $21-30$ years is $126,31-40$ years is 50 and $>40$ years is 0 , as shown in Table 2.

Among the study group, 218 women got NT scanning done between 11 week 0 day and 11 week 6 days, 508 women between 12 week 0 day and 12 week 6 days, and 396 women between 13 week 0 day and 13 week 6 days.

Figure 3 shows that among the study group, 229 women fall in the CRL value of $41-50 \mathrm{~mm}, 324$ women in $51-60 \mathrm{~mm}, 465$ women in $61-70 \mathrm{~mm}$, and 104 women in $71-80 \mathrm{~mm}$.

\section{Discussion}

All mothers presenting at Kasturba Medical College Hospitals and Govt. Lady Goschen Hospital who undergone routine antenatal scan from 11 weeks to 13 weeks 6 days of gestation for NT were enrolled in the study and followed up till birth.

Our study subjects underwent NT scanning between 11 weeks and $13^{+6}$ weeks of gestation according to LMP.

Among the study group, 218 women got NT scanning done between 11 week 0 day and 11 week 6 days, 508 women between 12 week 0 day and 12 week 6 days, and 396 women between 13 week 0 day and 13 week 6 days.

Among the study group, 229 women fall in the CRL value of 41-50 mm, 324 women in 51-60 mm, 465 women in $61-70 \mathrm{~mm}$, and 104 women in $71-80 \mathrm{~mm}$.

Screen positive groups were defined by a cutoff in fetal NT as taking 95th (Comas et al. 2002), 99th centile (Economides et al. 1998),

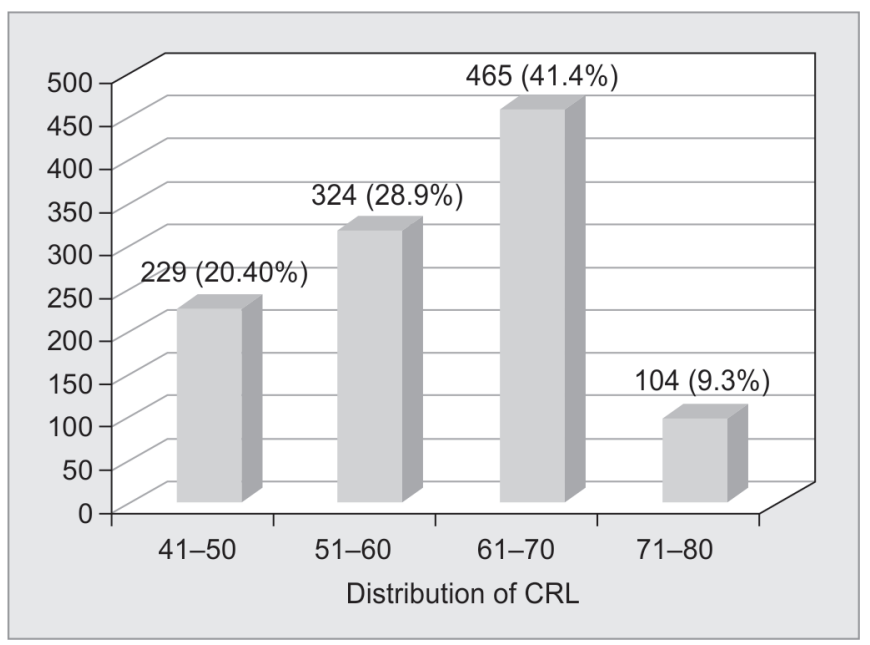

Fig. 3: Distribution of CRL among a study group $(n=1,122)$

NT measurements as $2.5 \mathrm{~mm}$ (Pandya et al. 1995) or $3 \mathrm{~mm}$ (Taipale et al. 1997) as cutoff value for the fetal CRL. ${ }^{16}$

Out of 70 congenital anomaly fetuses, multiple organ involvement is noted in 11 fetuses and single organ involvement in 59 fetuses. In our study population, 605 women are primigravida and 517 women are multigravida. Out of 1,122 study subjects, 149 women had previous history of miscarriages and 973 women had no previous miscarriage history. ${ }^{17-35}$

The number of pregnancies with NT thickness $>95$ th centile and an estimated risk for trisomy 21 that was based on fetal NT and crown-rump length is $90.9 \%$. The trisomy 18 estimated risk was $9.1 \%$ with NT thickness $>95$ th centile. Other trisomies were not documented in our study.

This establishes the role of first-trimester screening for the NT value at 11 weeks to 13 weeks 6 days in anticipating aneuploidies and structural abnormalities.

\section{Conclusion}

Ultrasound is an excellent tool for detection of aneuploidy. It also helps in detection of structural abnormalities. In our study, we used TAS for antenatal mothers as patient acceptability is less with TVS.

We have done NT scan from 11 weeks to $13^{+6}$ weeks of gestation, in our study; the mean examination time of the NT scan was 12 weeks 3 days (SD $=4.832$ ) according to patients' LMP.

Mean NT is $2.204 \mathrm{~mm}$ and standard deviation is $1.1028 \mathrm{~mm}$. The cutoff value for NT is taken as $3 \mathrm{~mm}$. The NT value less than $3 \mathrm{~mm}$ is considered as normal and the NT value more than $3 \mathrm{~mm}$ is considered as the high NT value.

Our study shows that as the NT value increases, the period of gestation of fetuses decreases proportionately ( $p$ value $<0.0001$ ).

This establishes a significant role of the NT value in pregnancy outcome and an important predictor of congenital anomalies. As there is a strong association with high NT values and congenital anomalies, routine NT scanning should be done between 11 weeks and 13 weeks and 6 days. This will guide the obstetrician to counsel the pregnant women and follow-up till termination of pregnancy.

\section{References}

1. Adams MM, Erickson JD, Layde PM, et al. Down's syndrome: recent trends in the United States. JAMA 1981;246(7):758-760. DOI: 10.1001/ jama.1981.03320070042022. 
2. Wald NJ, Kennard A, Hackshaw AK, et al. Antenatal screening for Down syndrome. J Med Screen 1997;4:181-246. DOI: 10.1177/096914139700400402.

3. Bromley B, Leibermann E, Shipp TD, et al. The genetic sonogram, a method for risk assessment for Down syndrome in the midtrimester. JUltrasound Med 2002;21(21):1087-1096. DOI: 10.7863/ jum.2002.21.10.1087.

4. Bromley B, Leibermann E, Shipp TD. Foetal nose bone length: a marker for Down syndrome in the second trimester. J Ultrasound Med 2002;21(12):1387-1394. DOI: 10.7863/jum.2002.21.12.1387.

5. Nicolaides KH, Snijders RJM, Gosden CM, et al. Ultrasonographically detectable markers of foetal chromosomal abnormalities. Lancet 1992;340(8821):704-705. DOI: 10.1016/0140-6736(92)92240-G.

6. Wald NJ, Densem JW, George L, et al. Prenatal screening for Down syndrome. Prenat Diagn 1996;16:143-153. DOI: 10.1002/(SICI)10970223(199602)16:2<143::AID-PD825>3.0.CO;2-F.

7. Nicolaides $\mathrm{KH}$. The $11-13^{+6}$ weeks scan. London: Foetal Medicine Foundation; 2004. pp. 15-17.

8. Nicolaides KH, Snijders RJM. Features of chromosomal defects. Diagnosis of foetal abnormalities-The 18-23 weeks scan. London; 2002. pp. 99-101.

9. Souka AP, Krampl E, Bakalis S, et al. Outcome of pregnancy in chromosomally normal foetuses with increased nuchal translucency in the first trimester. Ultrasound Obstet Gynecol 2001;18(1):9-17. DOI: 10.1046/j.1469-0705.2001.00454.x.

10. Brigatti KW, Malone FD. First trimester screening for Aneuploidy. Obstet Gynecol Clin N Am 2004;31(1):6-7. DOI: 10.1016/S08898545(03)00119-0.

11. Scott F, Boogert A, Sinosich M, et al. Establishment and application of a normal range for nuchal translucency across the first trimester. Prenat Diagn 1996;16(7):629-634. DOI: 10.1002/(SICI)10970223(199607)16:7<629::AID-PD922>3.0.CO;2-X.

12. Snijders RJM, Nobel P, Sebire N, et al. UK multicentre project on assessment of risk of trisomy 21 by maternal age and foetal nuchal translucency thickness at 10-14 weeks of gestation. Lancet 1998;351(9125):343-346. DOI: 10.1016/S0140-6736(97) 11280-6.

13. Souka AP, Snijders RJM, Novakov A, et al. Defects and syndromes in chromosomally normal foetuses with increased nuchal translucency at 10-14 weeks of gestation. Ultrasound Obstet gynecol 1998;11(6):391-400. DOI: 10.1046/j.1469-0705.1998.11060391.x.

14. Vintzileos AM, Ananth CV, Smulian JC, et al. Cost benefit analysis of prenatal diagnosis for Down syndrome using the British or the American approach. Obstet Gynecol 2000;95:577-583. DOI: 10.1016/ S0029-7844(99)00613-4.

15. Nicolaides KH, Azar G, Byrne D, et al. Foetal NT: Ultrasound screening for chromosomal defects in the first trimester of pregnancy. BMJ 1992;304:867-869. DOI: 10.1136/bmj.304.6831.867.

16. Pandya PP, Kondylios L, Hilbert L, et al. Chromosomal defects and outcome in 1015 foetuses with increased NT. Ultrasound Obstet Gynecol 1995;5(1):15-19. DOI: 10.1046/j.1469-0705.1995.05010015.x.

17. Wayda K, Keresztúri A, Orvos $\mathrm{H}$, et al. Four years experience of firsttrimester nuchal translucency screening for foetal aneuploidies with increasing regional availability. Acta Obstet Gynecol Scand 2001;80(12):1104-1109.

18. Bethune M. Literature review and suggested protocol for managing ultrasound soft markers for Down syndrome: thickened nuchal fold, echogenic bowel, shortened femur, shortened humerus, pyelectasis and absent or hypoplastic nasal bone. Australiasian Radiol 2007;51(3):218-225. DOI: 10.1111/j.1440-1673.2007.01713.x.

19. BromleyB, Lieberman E, ShippTD, etal. The genetic sonogram:a method of risk assessment for Down syndrome in the 2 nd trimester. J Ultrasound Med 2002;21(10):1087-1096. DOI: 10.7863/jum.2002.21.10.1087.

20. Pajkrt E, De Graff IM, Mol BWJ, et al. Weekly nuchal translucency measurements in normal foetuses. Obstet Gynecol 1998;91:208-211. DOI: 10.1016/S0029-7844(97)00658-3.

21. Wald NJ, Hackshaw AK, Huttly W. Screening for Down's syndrome: Serum screening programmes are effective and safe. BMJ 2000;321:763-764.

22. Cuckle H. Screening for Down syndrome: Statistical modelling is the best tool for formulating screening policy [letter]. BMJ 2000;321: 763.

23. Nicolaides $\mathrm{KH}$. The $11-13^{+6}$ weeks scan. London: Foetal medicine foundation; 2004. pp. 24-25.

24. Sonek J. First trimester ultrasonography in screening and detection of foetal anomalies. Am J Med Genet Part C Semin Med Genet 2007;145C(1):45-61. DOI: 10.1002/ajmg.c. 30120.

25. Hyett JA, Perdu M, Sharland GK, et al. Increased nuchal translucency at 10-14 weeks of gestation as a marker for major cardiac defects. Ultrasound Obstet Gynecol 1997;10(4):242-246. DOI: 10.1046/j.14690705.1997.10040242.x.

26. Ogle RF, Chitty LS. Prenatal screening for Down syndrome. Hospital Medicine 1998;59(8):632-636.

27. Nicolaides $\mathrm{KH}$, Snijders RJM. Features of chromosomal defects. Diagnosis of foetal abnormalities - the 18-23 weeks scan. London; 2002. pp. 100-102.

28. Morris JK, Wald NJ, Watt HC. Foetal loss in Down syndrome pregnancies. Prenat Diagn 1999;19(2):142-145. DOI: 10.1002/ (SICI)1097-0223(199902)19:2<142::AID-PD486>3.0.CO;2-7.

29. Down LJ, Observations on an ethnic classification of idiots. Clin Lectures and Reports, London Hospital. 1866;3:259-262.

30. Kypros $\mathrm{H}$. Nicolaides, The $11-13^{+6}$ weeks scan. London: Foetal Medicine Foundation; 2004. p. 21.

31. Nicolaides $\mathrm{KH}$. Screening for Chromosomal defects. Ultrasound Obstet Gynecol 2003;21:313-321. DOI: 10.1002/uog.128.

32. Nicolaides KH. Nuchal Translucency and other 1st trimester sonographic markers of chromosomal abnormalities. Am J Obstet Gynecol 2004;191(1):45-67. DOI: 10.1016/j.ajog.2004.03.090.

33. Hook EB. Rates of chromosome abnormalities at different maternal ages. Obstet Gynecol 1981;58(2):282-285.

34. Hook EB, Cross PK, Schreinemachers DM. Chromosomal abnormality rates at amniocentesis and in live-born infants. JAMA 1983;249(15):2034-2038. DOI: 10.1001/jama.1983.03330390038028.

35. Nyberg DA, Mack LA, Hirsch J, et al. Foetal hydrocephalus: sonographic detection and clinical significance of associated anomalies. Radiology 1987;163(1):187-191. DOI: 10.1148/radiology.163.1.3547493. 